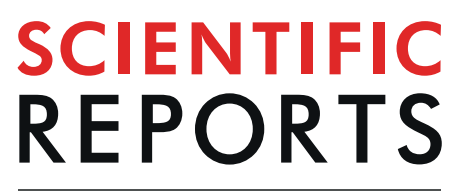

natureresearch

\title{
The trends in land surface heat fluxes over global monsoon domains and their responses to monsoon and precipitation
}

Jian Zeng $\mathbb{1}^{1,2}$ \& Qiang Zhang ${ }^{1,2,3 *}$

The climatology, trends and leading modes of land surface latent heat flux (LHF) and sensible heat flux (SHF) as well as their responses to monsoon and precipitation in global land monsoon domains are presented. During the past three decades, LHF and SHF have generally undergone a rising and decreasing trend (that is, (LHF+, SHF-)), respectively, in Asian, North African, Austrian, and South American monsoon domains. Moreover, the increasing rate of LHF was higher than the decreasing rate of SHF, which causes a decreased trend in Bowen ratio. Two other dominant trend patterns, (LHF-, $\mathrm{SHF}-$ ) and ( $\mathrm{LHF}+$, SHF+), are observed in South African and South American monsoon domains, respectively. The trends in LHF and SHF are closely linked to increasing global monsoon intensity and precipitation, especially for the monsoon domain that has annual precipitation lower than $1300 \mathrm{~mm} \mathrm{yr}^{-1}$. Singular value decomposition (SVD) analyses show that monsoon strength explains $\mathbf{2 5 . 2} \%$ and $\mathbf{2 2 . 2 \%}$ total covariance of LHF and SHF respectively in the first modes, and that precipitation slightly raises the percentages up to $27.8 \%$ and $24 \%$ respectively. The increasing monsoon and precipitation on one hand favor more land surface available energy being converted into LHF; on the other hand they enhance the LHF by increasing the land surface net radiation. Moreover, remarkable phase shifts in LHF and SHF are observed for monsoon domains during late-1990s, which are in phase with those of precipitation and monsoon strength. The intensifying LHF and precipitation indicate the acceleration of hydrological cycle in global terrestrial monsoon domains.

Land surface heat fluxes, including latent heat flux (LHF) and sensible heat flux (SHF), link the land surface with the atmosphere by transporting land surface energy and moisture into the atmosphere. Therefore, they are critical parts of water and energy cycles, and govern the land-atmosphere interactions.

Land surface conditions including soil moisture and green vegetation fractions significantly impact the land-atmosphere linkage by dominating the partitioning of land surface available energy into LHF and SHF. The partitioning of land surface available energy is often described by the ratio of SHF to LHF, known as the Bowen ratio. Bowen ratio alone can reflect the relative magnitudes of SHF and LHF as well as the land surface thermal-hydrologic properties. Wetter land surface and larger vegetation fractions favor higher LHF and smaller SHF, resulting in a smaller Bowen ratio. For instance, the Bowen ratio is found to be 0.61 during dry winter season but it reduces to 0.18 during summer monsoon season for cropland ${ }^{1}$. For irrigation-dependent agricultural region, the ratio can even reach as low as $0.01^{2}$. The energy partitioning that contains the information of land surface thermal-hydrologic properties further exerts influences on atmosphere by initially modifying boundary layer structure including the stability and height, which finally significantly affects atmospheric circulations, precipitation and climate on local, regional or larger scales ${ }^{3-6}$. Therefore, the land surface energy partitioning is closely related to climate variability.

Over land, however, the thermal-hydrologic properties of land surface are significantly regulated by precipitation. LHF and SHF are thus closely linked to precipitation. Moreover, precipitation and the moisture transported via LHF (or evapotranspiration) are the two key components of land surface hydrological balance. The

${ }^{1}$ College of Atmospheric Sciences, Lanzhou University, Lanzhou, China. ${ }^{2}$ Key Laboratory of Arid Climatic Change and Disaster Reduction in Gansu Province, Key Open Laboratory of Arid Climatic Change and Disaster Reduction in CMA, Institute of Arid Meteorology, CMA, Lanzhou, China. ${ }^{3}$ Gansu Provincial Meteorological Bureau, Lanzhou, China. *email: zhangqiang@cma.gov.cn 


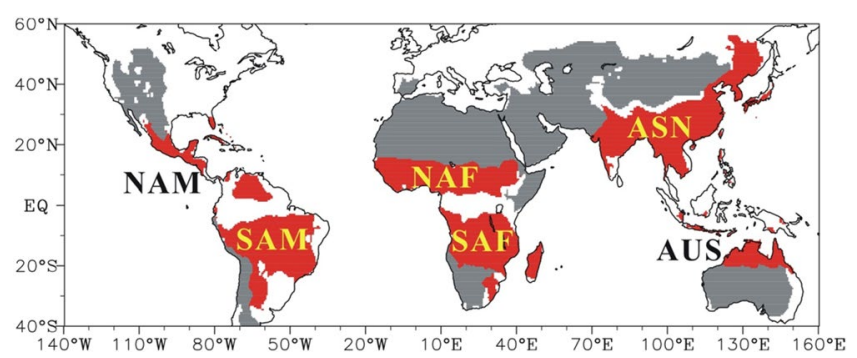

Figure 1. The global monsoon domains on land (red). The drylands are shaded in grey. Drylands are defined as regions where the annual precipitation $\mathrm{P}<600 \mathrm{~mm}$ and ratio of annual precipitation to potential evapotranspiration $\mathrm{P} / \mathrm{PET}<0.65^{45}$.

LHF-precipitation feedback is the most uncertain part of soil moisture-precipitation feedback, as well as the most difficult to ascertain given the number of processes involved ${ }^{7}$. Therefore, the LHF and precipitation couplings are the crucial step in the soil moisture-precipitation feedback loop, and require further investigations.

The global monsoon domains, located primarily in tropics and characterized by abundant precipitation, are crucial sources of land surface heat fluxes. Global monsoon is a powerful system and exerts prominent influences on regional and global weather and climate. Over half of the globe's population, most in developing countries, lives under the impacts of monsoon-dominated climates ${ }^{8}$. In these regions, monsoonal precipitation provides the majority of fresh water for agriculture and ecosystems. With the global warming, the global monsoonal precipitation has significantly increased in the recent decades ${ }^{9-11}$. In future, the annual mean and range of global monsoonal precipitation and the percentage of summer rainfall are projected to continue to intensify at a significant level over most of the global regions ${ }^{12}$. The increasing precipitation should alter the land surface energy partitioning and thus, the water and energy cycles and the linkage between the land and the atmosphere, although to what extent remains unknown. Furthermore, land surface energy fluxes, in turn, are crucial for understanding the increasing trends in monsoonal precipitation.

However, the variability and long-term trends of land surface heat fluxes are not yet well investigated in global monsoon domains ${ }^{13}$. The responses of land surface heat fluxes to monsoon and monsoonal precipitation is not clear either. This is primarily due to a lack of reliable observations, although great efforts have been made to estimate the LHF and SHF. Various satellite remote sensing approaches have been applied to characterize their spatio-temporal variations, but so far only short-duration products are available and have the problems of questionable accuracy ${ }^{14}$. In the past two decades, eddy covariance (EC) measurement networks have been established and land surface heat fluxes from these observations networks are more reliable ${ }^{15,16}$. But they are limited by sparse spatial resolution. Jung et al. have recently upscaled the current FLUXNET observations of LHF and SHF using machine learning technique and model tree ensembles ${ }^{17}$. Cross-validation analyses show that the gridded FLUXNET have good performance in representing among-site flux variability and seasonal patterns ${ }^{18}$. Therefore, this dataset offers an opportunity to study the variability of the terrestrial LHF and SHF, and helps understand the water and energy cycling in global monsoon domains.

This paper primarily aims to survey the spatial patterns of land surface energy partitioning over global monsoon domains, investigate their variations and trends under increasing precipitation and global warming during the past three decades, and discuss the response of land surface energy partitioning to monsoon and precipitation.

\section{Method and Data}

Determination of global monsoon domains over land. Conventionally, the terminology "monsoon" was defined by the seasonal shift of prevailing winds between winter and summer ${ }^{19}$. The term now also increasingly refers to regions where there is a clear precipitation contrast between rainy phase (summer) and dry phase (winter) ${ }^{20}$. Therefore, the global monsoon domains over land are defined by the annual precipitation range followingWang and Ding ${ }^{21}$. Specially, the global monsoon domains refer to the regions where the annual range of precipitation between wet and dry seasons exceeds $2.5 \mathrm{~mm}_{\text {day }}^{-1}$ and the wet seasonal precipitation contributes more than $55 \%$ of the total annual precipitation. The wet season denotes May-September (November-March) for the Northern (Southern) Hemisphere, while the dry season is the opposite. The global monsoon domains defined by annual precipitation range are shown in Fig. 1. They can be divided into six sectors, including the Asian (ASN), North African (NAF), and North American (NAM) monsoon sectors in the Northern Hemisphere (NH), as well as the Austrian (AUS), South African (SAF), and South American (SAM) monsoon sectors in the Southern Hemisphere $(\mathrm{SH})$.

Data. The land surface latent heat flux (LHF) and sensible heat flux (SHF) are provided by the gridded FLUXNET dataset. The gridded FLUXNET dataset is derived from continuous in-situ measurements of FLUXNET, remote sensing and meteorological observations based on model tree ensembles ${ }^{18}$. This dataset covers a period of 30 years $(1982-2011)$ at $0.5^{\circ} \times 0.5^{\circ}$ spatial and monthly temporal resolution. Here the gridded FLUXNET dataset is validated by observations from eddy covariance system at nine land surface in-situ sites in monsoon domains (Table 1). These representative observation sites are well maintained and the observed LHF and SHF are under strict quality control. Necessary procedures for corrections and quality control of the turbulent fluxes are implemented during post-field data processing. Their detailed information is listed in Table 1. As shown in Fig. 2, the gridded FLUXNET dataset performs well in representing the LHF and SHF. The correlation 


\begin{tabular}{|l|l|l|l|l|}
\hline Site name & Latitude $\left(^{\circ}\right)$ & Longitude $\left(^{\circ}\right)$ & Vegetation type & $\begin{array}{l}\text { Observation } \\
\text { period }\end{array}$ \\
\hline Kennedy Space Center Scrub Oak & 28.609 & -80.672 & Closed shrubland & $2000-2006$ \\
\hline Kennedy Space Center Slash Pine Flatwoods & 28.458 & -80.671 & Evergreen needleleaf forest & $2002-2003$ \\
\hline Mize & 29.765 & -82.245 & Evergreen needleleaf forest & $1998-2004$ \\
\hline Freeman Ranch Mesquite Juniper & 29.950 & -97.996 & Woody savanna & $2004-2006$ \\
\hline Donaldson & 29.755 & -82.163 & Evergreen needleleaf forest & $1999-2004$ \\
\hline Dinghushan & 23.150 & 112.500 & Evergreen broadleaf forest & $2003-2002$ \\
\hline Qianyanzhou & 26.730 & 115.500 & Evergreen needleleaf forest & $2003-2003$ \\
\hline Xishuangbanna & 21.900 & 102.267 & Evergreen broadleaf forest & $2003-2004$ \\
\hline Yucheng & 36.858 & 116.640 & Cropland & $2003-2005$ \\
\hline
\end{tabular}

Table 1. Details of the observation sites.

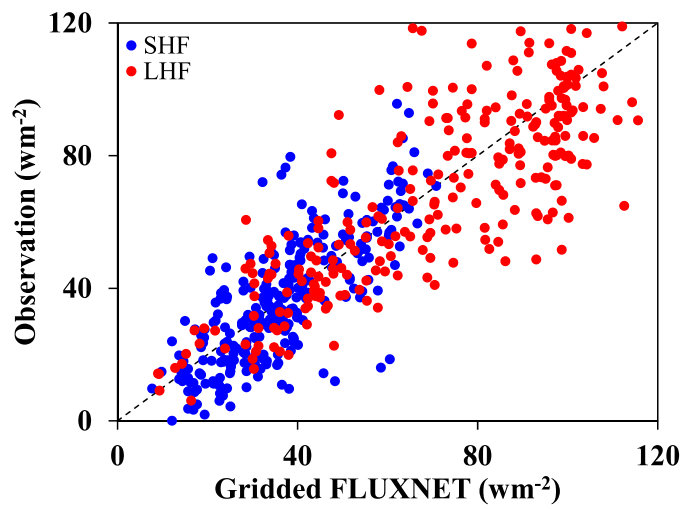

Figure 2. Comparisons of monthly LHF and SHF between the gridded FIUXNET and observations from nine in-situ sites.

coefficients between the observations and the gridded FLUXNET are 0.78 and 0.76 for LHF and SHF, respectively, which is in line with the previous studies ${ }^{22,23}$. The root mean square error (RMSE) is 1.06 and $1.70 \mathrm{MJ} \mathrm{m}^{-2}$ day $^{-1}$ for LHF and SHF, respectively. The RMSE for LHF is higher than the $0.7 \mathrm{MJ} \mathrm{m}^{-2}$ day $^{-1}$ of Yang et al. partly due to sample size and observation errors ${ }^{22}$, but it is acceptable for climatology and trend analyses. Moreover, cross-validation analyses also show that gridded FLUXNET SHF and LHF have good performance in representing among-site flux variability and seasonal patterns ${ }^{18}$. Therefore, the gridded FLUXNET dataset provides good and reliable estimates of LHF and SHF. Notably, the ground heat flux is not available from the gridded FLUXNET dataset. But the ground heat flux has opposite signs during daytime and nighttime, and during warm and cold seasons. Since the annual data is used, the impact of ground heat flux may be negligible.

Monthly precipitation is taken from the Climatic Research Unit Timeseries (CRU TS) compiled by the CRU ${ }^{24}$. In this paper, the version CRU TS 4.01 is used, which was released in September 2017. This dataset, based on analysis of over 4000 individual weather station records, spans the period January 1901 to December 2016 at $0.5^{\circ}$ $\times 0.5^{\circ}$ spatial resolution and on monthly scale. Compared to its previous versions 3.xx, this new version switches from triangulated linear interpolation to Angular Distance Weighting for gridding the monthly anomalies, which allows total control over how station observations are selected for gridding. Harris et al. compared the precipitation data from CRU to that from the Global Precipitation Climatology Centre (GPCC) dataset ${ }^{24}$. Close agreement for precipitation was demonstrated between CRU and the GPCC dataset in many sub-continental regions, except for the first 50 years (1901-1950). CRU dataset has been used for drought assessments ${ }^{25-27}$, climate change assessments $^{28,29}$, and climate trend ${ }^{30}$.

Simple measurement of global monsoon strength. Similar to Hsu et al. ${ }^{9}$, here we take the annual range of precipitation between summer/warm and winter/cold seasons as a measurement of monsoon strength. But we find this measurement may lead to mislead in the strength for monsoon sectors that have abundant rainfall for both summer and winter seasons. For example, the strongest monsoon is observed in sectors SAM and NAM (that is, largest annual range of precipitation) based on annual range of precipitation, which is inconsistent with the conventional notions (Fig. S1). Therefore, we improve the measurement approach by excluding the impact of background precipitation. The annual range is normalized by the climatological annual precipitation to define the monsoon strength $\delta$ (Eq. 1). Under the improved definition, the monsoon strength is $1.94,1.65,1.64$, $1.45,1.37$, and 1.18 for AUS, NAF, SAF, ASN, SAM and NAM, respectively. The monsoon is weakest in SAM and NAM and strongest in AUS. The NAF, SAF and ASN are in-between. Since the annual range of precipitation (in $\left.\mathrm{mm} \mathrm{d}^{-1}\right)$ is adopted to define monsoon domains, $\delta$ can to large extent reflect the intensity of monsoon. According to the definition, a large (small) $\delta$ means active (inactive) monsoon. Figure 3 presents its temporal variation along 


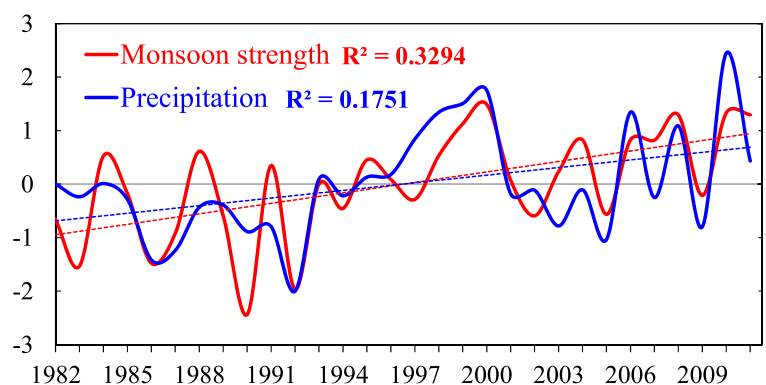

Figure 3. The time series of normalized monsoon strength (red solid line) and precipitation (blue solid line) in global land monsoon domains. The dashed lines are the linear trends for monsoon strength and precipitation, which are statistically significant at $99 \%$ and $95 \%$ confident level, respectively. The determination coefficients $\left(R^{2}\right)$ for the linear fitting are also presented.

with precipitation in global land monsoon domains. Both the monsoon strength and precipitation show a statistically significant enhancement in the past 30 years, at $99 \%$ and $95 \%$ confident level, respectively.

$$
\delta=\frac{P_{\text {summer }}-P_{\text {winter }}}{\overline{P_{\text {climatology }}}}
$$

Here $\delta$ denotes the monsoon strength. $P_{\text {summer }}$ and $P_{\text {winter }}$ are the total precipitation for summer and winter, respectively. $\overline{P_{\text {climatology }}}$ is the long-term mean annual precipitation.

In fact, the annual range of precipitation has been accepted and frequently used to defined the monsoon strength in previous works ${ }^{31,32}$. The definition of the global monsoon strength based on precipitation essentially reflects the seasonal change of prevailing wind ${ }^{32}$. Moreover, global monsoon strength based on precipitation significantly $(\mathrm{r}=0.85)$ correlates with monsoon intensity measured by the vertical shear of zonal wind and varies in phase with Hadley circulation intensity (Wang et al., 2013). Therefore, $\delta$ can provide reasonable and simple measurement of monsoon activity, and reflect both of the seasonal changes of prevailing wind and monsoonal precipitation.

\section{Climatology of LHF and SHF}

The global monsoon domains are crucial sources of land surface heat fluxes. Figure 4 shows the long-term annual mean LHF, SHF, and Bowen ratio (the ratio of SHF to LHF) during 1981 to 2011. As expected, the land surface available energy is largely consumed by the LHF in monsoon domains. The mean annual LHF for monsoon domain is $2000.5 \mathrm{MJ} \mathrm{m}^{-2} \mathrm{yr}^{-1}$, comparing with $1506.6 \mathrm{MJ} \mathrm{m}^{-2} \mathrm{yr}^{-1}$ of SHF. But significant regional differences in land surface energy partitioning are observed among six monsoon domains. The monsoon sectors SAM and NAM have the largest LHF, followed by SAF and NAF, ASN and AUS. The mean annual LHF in six monsoon sectors ranges from 1411.7 to $2462.7 \mathrm{MJ} \mathrm{m}^{-2} \mathrm{yr}^{-1}$. In contrast, AUS has the highest SHF, followed by NAF and SAF, NAM, ASN and SAM. The mean annual SHF ranges from 1170.6 to $2055.8 \mathrm{MJ} \mathrm{m}^{-2} \mathrm{yr}^{-1}$. Therefore, Bowen ratio is highest in AUS, followed by NAF and SAF, ASN, NAM and SAM. Notably the long-term mean SHF is larger than LHF in AUS and thus, AUS is the only monsoon sector that has Bowen ratio above 1, which seems contradictory to the fact that AUS has the strongest monsoon. In fact, a monsoon includes a dry phase and a rainy phase. The definitions of monsoon and monsoon strength emphasize the seasonal change but not its rainy season alone. This can also explain why NAM and SAM has the weakest monsoon but its Bowen ratio is lowest. It is evident that the differences in LHF, SHF and Bowen ratio among six sectors are continental. SAF and NAF, located in the African continent, have similar LHF, SHF and Bowen ratio, and the same case for SAM and NAM which belong to the American continent. But there exist significant differences between African and American monsoon sectors, which reflect the contribution of radiation budget and background climates on land surface heat exchanges. In fact when LHF, SHF and Bowen ratio are normalized by their maximums in each monsoon sector, the regional differences in normalized LHF, SHF, and Bowen ratio among six monsoon sectors are negligible.

Besides, high LHF is one of the prominent features that separate monsoon from most of non-monsoon regions. As shown in Fig. 5, monsoon domains have much larger LHF than non-monsoon regions, while no significant contrast in SHF is seen. Therefore, Bowen ratio is much smaller in monsoon regions.

\section{Trends in LHF and SHF}

With the global warming, land surface fluxes show obvious trends in global monsoon domains. Figure 6 displays the spatial pattern of linear trends in LHF, SHF and Bowen ratio for the past 30 years (1982-2011). Increased trends in LHF are dominant in all monsoon sectors except SAF. More than $82 \%$ of land areas in ASN and NAF undergo an increase in LHF, and the fractions for AUS, NAM and SAM are 63\%, 69\% and 67\% respectively. However, the percentage of land with rising trend is only $32 \%$ in SAF, indicating most areas of SAF had experienced a decrease in LHF. The median trends are 1.25, 3.47, $-0.98,1.26,0.71$, and $0.92 \mathrm{MJ} \mathrm{m}^{-2} \mathrm{yr}^{-1} \mathrm{yr}^{-1}$ for ASN, NAF, SAF, AUS, NAM, and SAM, respectively (Fig. 7). As for SHF, both the decreased and increased trends take up a significant portion in monsoon regions, but the decreased trend seems more dominant. About $61 \%$ area is in decreased trend of SHF for ASN, SAF, AUS, and NAM. More than 50\% area in SAM and NAF undergo upward trends in SHF. The median trends in SHF are $-0.45,-0.41,-0.72,-0.90,-0.01$, and $0.44 \mathrm{MJ} \mathrm{m}^{-2} \mathrm{yr}^{-1} \mathrm{yr}^{-1}$ for 

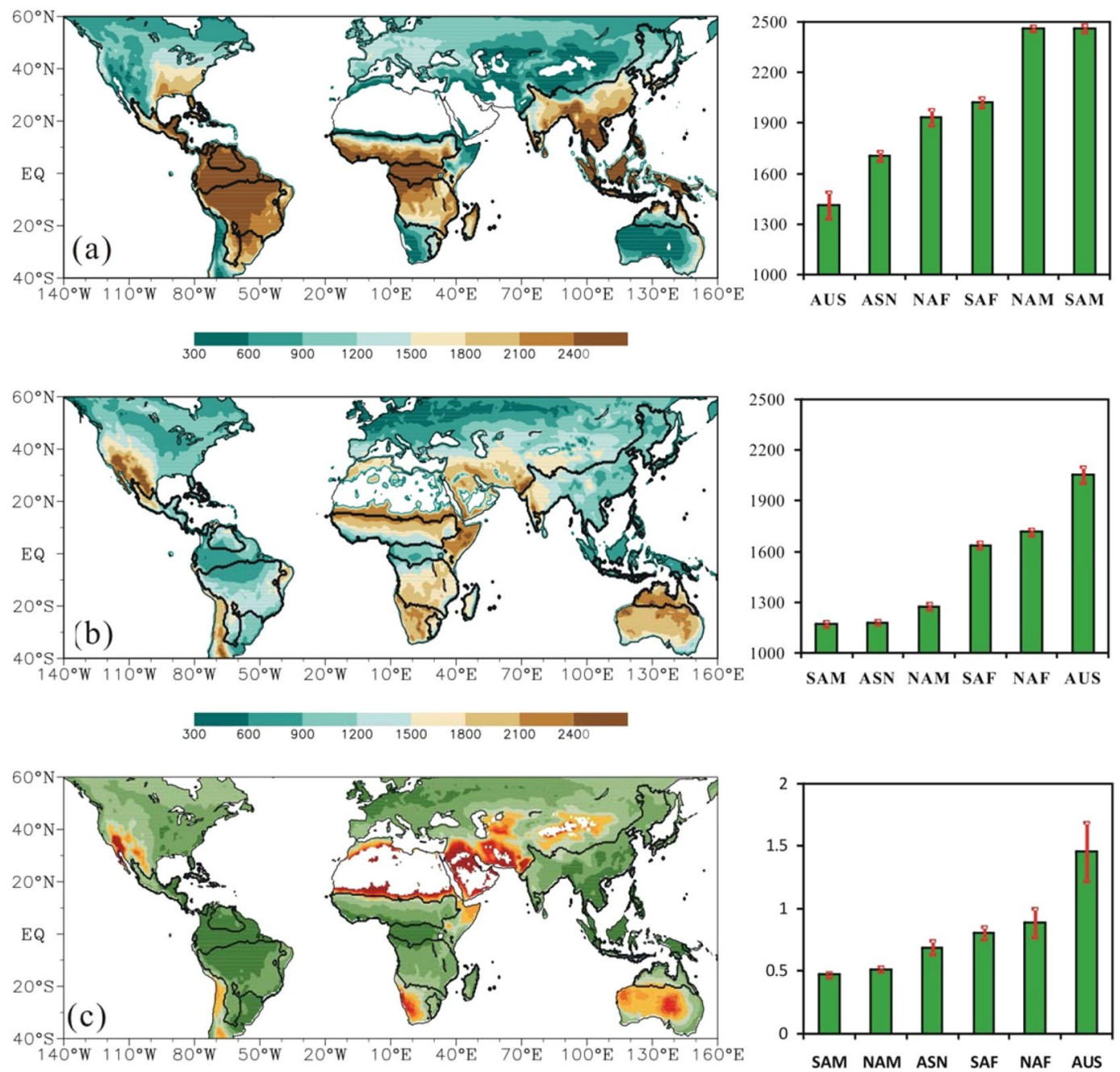

Figure 4. Climatology of (a) LHF, (b) SHF, and (c) Bowen ratio. The global monsoon domains are outlined by bold contours and the histograms show the regional averages of six monsoon sectors. The unit of LHF and SHF is $\mathrm{MJ} \mathrm{m} \mathrm{m}^{-2} \mathrm{yr}^{-1}$. The red bars in the columns are the standard deviations.

ASN, SAF, AUS, NAM, NAF, and SAM, respectively. It is apparent that trends in SHF are in the opposite direction to trends in LHF for most of monsoon domains, which is expected because LHF will cool the land surface and narrow the land-atmosphere temperature difference. Moreover, the decreasing rates of SHF are much smaller than the increasing rate of LHF in monsoon domains, which implies the increased LHF is only partially from the decreased SHF and the remaining may be associated with an increase in land surface net radiation. As shown in Fig. $6 \mathrm{~d}$, the land surface net radiation derived from $\mathrm{NCEP}^{33}$ has undergone a rising trend in most of global monsoon domains over the past 30 years, which is in concert with previous study that the surface net radiation over land may have increased by about $2 \mathrm{~W} \mathrm{~m}^{-2}$ decade $^{-1}$ during 1986 and $2000^{34}$. This may be also partially attributed to the global brightening since $1990 \mathrm{~s}^{35}$. The Bowen ratio thus weakens for most of monsoon domains because of the faster increasing rate in LHF than the decreasing rate in SHF. The exceptions are the SAF and SAM. Bowen ratio shows an increased trend in about $58 \%$ area in SAF due to the weaker decreased rate of SHF than that of LHF. However in SAM, where the increased trends are dominant for both LHF and SHF, the percentages for upward and downward trends in Bowen ratio are almost equally shared. The median trends in Bowen ratios are $-0.0007,-0.0016,0.0003,-0.001,-0.0005$, and $0.0 \mathrm{yr}^{-1}$ for ASN, NAF, SAF, AUS, NAM and SAM, respectively.

Consequently, there are three dominant types of trends in land surface fluxes among six monsoon sectors (Fig. 8a). The first is increasing LHF and decreasing SHF (that is, (LHF+, SHF-)), which occurs in $41.6 \%$ land area in the global monsoon domains and is the dominant trends in monsoon sectors ASN, AUS, NAM, NAF. This is consistent with the increasing moisture gradient and decreasing temperature gradient between land surface and 2-m air in monsoon domains based on Era-interim reanalysis dataset ${ }^{36}$ (Fig. S2a,b). In contrast, the trend (LHF-, SHF+) is observed in only $17.8 \%$ land area and is not dominant in any monsoon sector. The second is the (LHF+, SHF +), which is observed in $24.5 \%$ of land area (including center and east of SAM, center SAF, and east of ASN) 

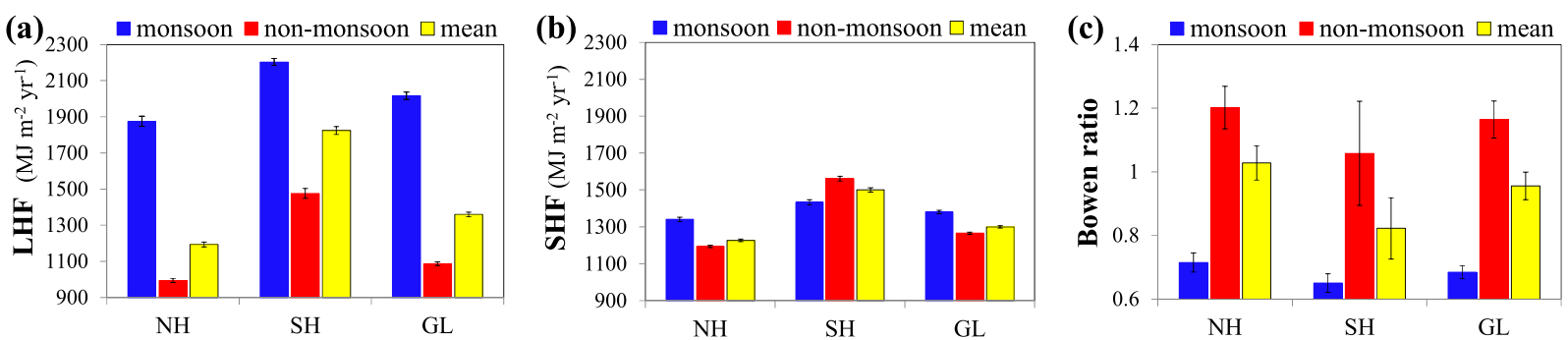

Figure 5. Long-term mean of annual (a) LHF, (b) SHF, and (c) Bowen ratio for monsoon, non-monsoon, and global domains during 1982-2011.
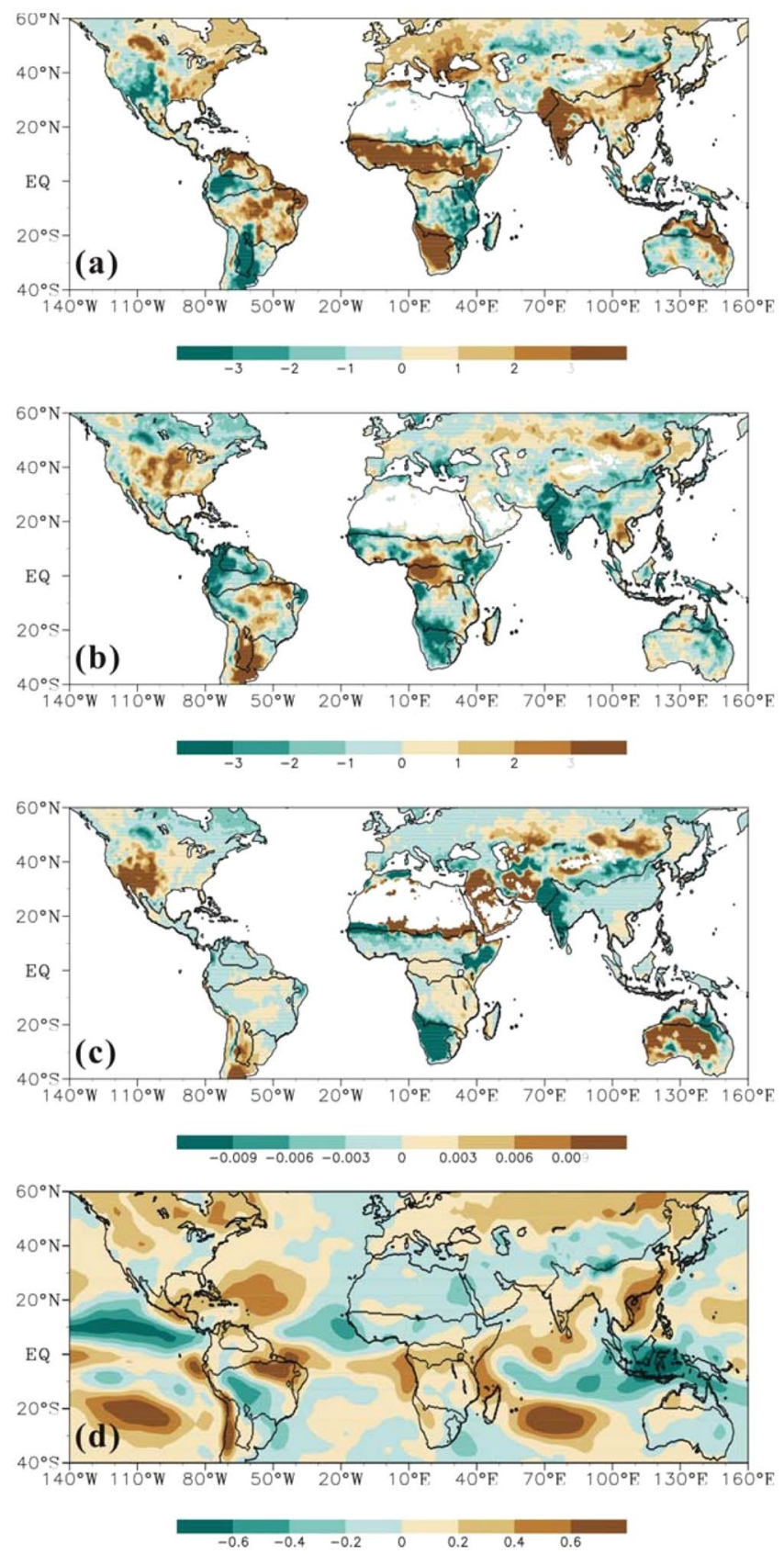

Figure 6. Trends for (a) LHF (in MJ m $\mathrm{m}^{-2} \mathrm{yr}^{-1} \mathrm{yr}^{-1}$ ), (b) SHF (in $\mathrm{MJ} \mathrm{m}^{-2} \mathrm{yr}^{-1} \mathrm{yr}^{-1}$ ), (c) Bowen ratio (in $\mathrm{yr}^{-1}$ ), and (d) net radiation (in $\mathrm{J} \mathrm{m}^{-2} \mathrm{yr}^{-1} \mathrm{yr}^{-1}$ ) during 1982-2011. The net radiation dataset is derived from NCEP. 

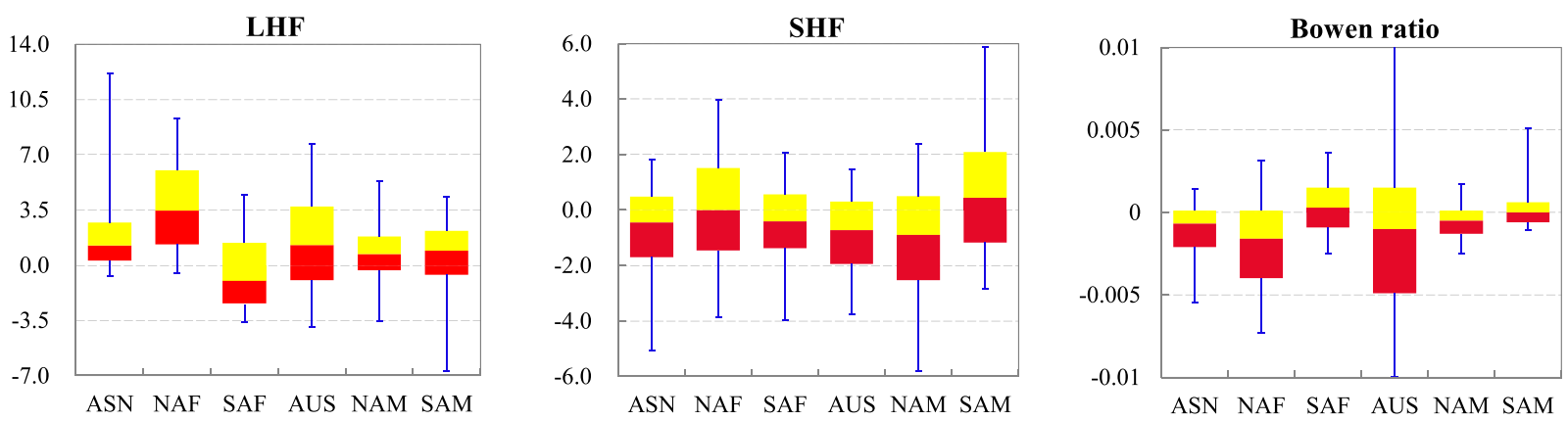

Figure 7. Box-and-whisker plots of trends for LHF (in $\mathrm{MJ} \mathrm{m}^{-2} \mathrm{yr}^{-1} \mathrm{yr}^{-1}$ ), SHF (in MJ m $\mathrm{m}^{-2} \mathrm{yr}^{-1} \mathrm{yr}^{-1}$ ), and Bowen ratio (in $\mathrm{yr}^{-1}$ ) within six monsoon domains during 1982-2011.

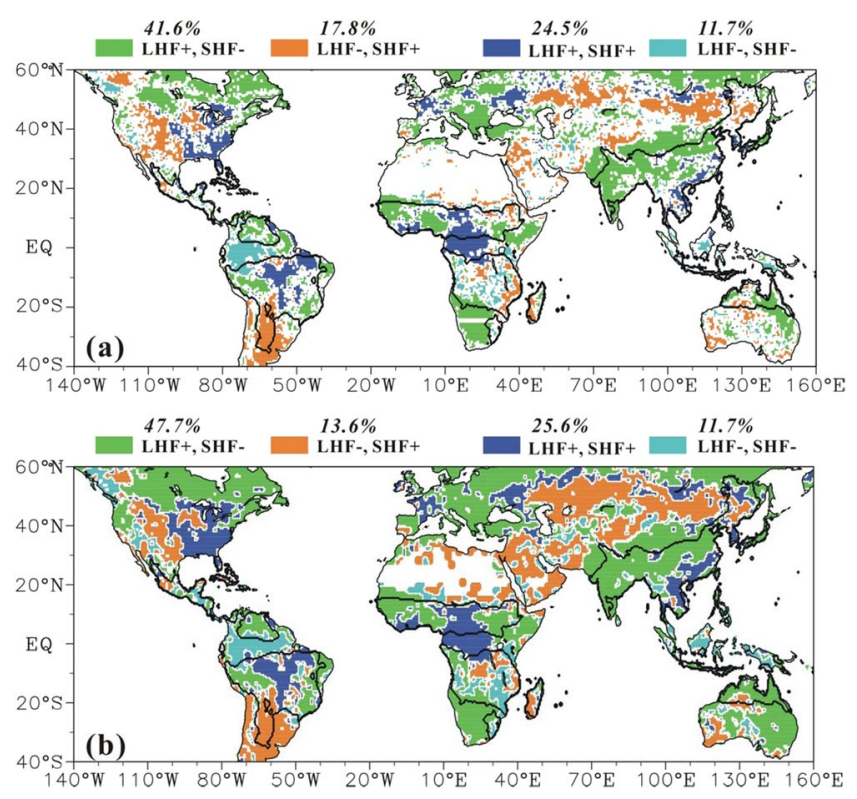

Figure 8. Statistics of the trend patterns in global terrestrial monsoon domains based on the (a) linear trends in LHF and SHF and (b) the primary SVD modes of LHF and SHF. The sign "+" denotes increasing trend, and "-" for decreasing trend.

and dominant in SAM. Notably, these regions all locate within the rainforest. The third is the (LHF-, SHF-), which is observed in $11.7 \%$ of land area and dominates in the SAF.

In addition, it is worth mentioning that not all of the trends in LHF, SHF and Bowen ratio are statistically significant. As presented in Fig. 9, trends in about 30\% area in SAF are statistically significant $(p<0.05)$ and the percentage is even lower than $20 \%$ in AUS. For the other four monsoon sectors, the percentages of significant trends range from $36 \%$ to $60 \%$. By comparison, fractions of significant trends in LHF are higher than that SHF and Bowen ratio in all monsoon sectors except the NAM.

Moreover, the trends in monsoon domains are different between the $\mathrm{NH}$ and $\mathrm{SH}$. The percentages of significant trends in LHF, SHF and Bowen ratio are all higher in NH monsoon domains (Fig. 9). As listed in Table 2, the trends for $\mathrm{NH}$ monsoon domains are at least one order of magnitude larger than that for SH monsoon regions, which is partly attributed to the opposite trend signs in SH monsoon sectors. We further investigate the regional average variations in LHF, SHF and Bowen ratio for six monsoon sectors. As presented in Fig. 10, no obvious trends are observed for monsoon sectors in SH, while significant increased trends in LHF and decreased trends in SHF and Bowen ratio are observed in NH. This may be related to the variability of monsoonal precipitation. The global monsoonal precipitation has significantly increased in the recent decades, especially in the $\mathrm{NH}$, mainly due to the significant rising trend of $\mathrm{NH}$ summer monsoon ${ }^{9-11}$. This is also partly associated with the intensified and weakened land surface wind speed in $\mathrm{NH}$ and $\mathrm{SH}$ monsoon domains, respectively (Fig. S2c). More notably, in contrast to monsoon regions, drylands experience opposite trends for both LHF and SHF, with a decreased trend in LHF and an increased trend in SHF (Fig. 6). This indicates LHF is becoming richer in monsoon regions but poorer in drylands, which is in line with the observed wet-get-wetter and dry-gets-drier precipitation trend patterns over the past 30 years $^{10}$. 


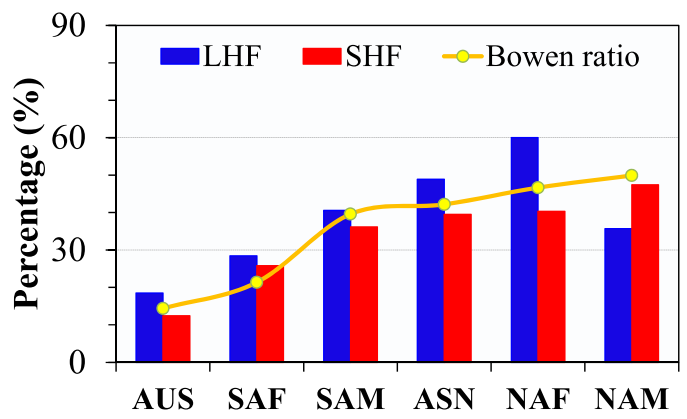

Figure 9. Percentages of land area that has statistically significant trend $(p<0.05)$ in LHF, SHF and Bowen ratio for six monsoon domains.

\begin{tabular}{|l|l|l|}
\hline & NH & SH \\
\hline LHF $\left(\mathrm{MJ} \mathrm{m}^{-2} \mathrm{yr}^{-1} \mathrm{yr}^{-1}\right)$ & $2.5 \mathrm{E}+00$ & $1.2 \mathrm{E}-02$ \\
\hline SHF $\left(\mathrm{MJ} \mathrm{m}^{-2} \mathrm{yr}^{-1} \mathrm{yr}^{-1}\right)$ & $-6.5 \mathrm{E}-01$ & $6.1 \mathrm{E}-02$ \\
\hline Bowen ratio $\left(\mathrm{yr}^{-1}\right)$ & $-2.2 \mathrm{E}-03$ & $5.6 \mathrm{E}-05$ \\
\hline
\end{tabular}

Table 2. Average trends in LHF, SHF and Bowen ratio for Northern Hemisphere (NH) and Southern Hemisphere (SH) during 1982 and 2011.

\section{The Influences of Monsoon Strength and Precipitation on Land Surface Energy Partitioning}

In monsoon domains, monsoon dominates the regional climate. Monsoonal precipitation provides the majority of fresh water for ecosystems and exerts significant influence on the land-atmosphere energy exchanges. With the global warming, the global monsoon and monsoonal precipitation have significantly increased in the recent decades (Fig. 3). As discussed above, the land surface fluxes in monsoon domains shows three dominant trend patterns, including the $(\mathrm{LHF}+, \mathrm{SHF}-),(\mathrm{LHF}+, \mathrm{SHF}+)$ and $(\mathrm{LHF}-, \mathrm{SHF}-)$. These variations in land surface fluxes may be connected to the intensifying monsoon and monsoonal precipitation. Evidently land surface conditions such as soil moisture are also critical for understanding the variation of land surface heat fluxes, but these thermal-hydrologic properties of land surface are significantly regulated by climate and circulations, such as monsoon and precipitation (Figs. S3,S4). Here we emphasize the responses of heat fluxes to monsoon and precipitation in monsoon domains. In this section, the singular value decomposition (SVD) analyses are applied to decompose the covariability between precipitation and LHF and SHF to assess the influences of monsoon and monsoonal precipitation on land surface energy partitioning. We focus on the spatial patterns of first modes for monsoon strength, precipitation, LHF and SHF, which are acquired by correlating them with the corresponding time series.

Coherent variations of precipitation and LHF, SHF and Bowen ratio. The first SVD mode between annual precipitation and LHF explains $27.8 \%$ of total covariance, which is much higher than that of the second mode $(10.8 \%)$ and third mode (8.3\%). As displayed in Fig. 11a, the pattern of LHF shows high spatial consistency with that of annual precipitation. Similar spatial coherence between precipitation and LHF trends are also reported by previous study ${ }^{37}$. The increase (decrease) in LHF is related to the increase (decrease) in precipitation. This is reasonable because precipitation can increase the humidity difference between the land surface and the near-surface atmosphere. Moreover, the spatial pattern of the first SVD mode of LHF in monsoon domains is highly matched by the pattern of LHF trends. This on one hand indicates that increased trends shown in Fig. 6a capture the primary variability of LHF; on the other hand it suggests that precipitation is one of main mechanisms contributing to the rising trends in LHF in monsoon sector ASN, NAF, NAM and AUS and the decreased trend for LHF in SAF. However, the eastern ASN (EASN) shows an increase in LHF with decreased precipitation, which agrees with findings of Qian et al. ${ }^{38}$. The possible reason is that precipitation has weak impact on evapotranspiration variability in some wet climate regimes where the evapotranspiration is radiation-limited. In fact EASN is not the only exception. Figure 12 presents the relations between annual LHF and precipitation on regional scale. The correlation coefficients between LHF and precipitation are $0.831,0.709,0.560,0.474,0.184,0.063$ and 0.009 for AUS, NAF, SAF, ASN, NAM, SAM and EASN respectively. One can see that the linear correlation between LHF and precipitation is much higher and statistically significant $(p<0.01)$ in AUS, NAF, SAF, and ASN, where the mean regional precipitation is below $1300 \mathrm{~mm} \mathrm{yr}^{-1}$. No significant correlation, however, is observed in EASN, SAM and NAM, where the mean regional precipitation is higher than $1400 \mathrm{~mm} \mathrm{yr}^{-1}$. The weak precipitation-LHF connection is also partly attributed to run-off, especially in SAM and NAM where part of precipitation runs into the wide-stretched Amazon River and the run-off increases remarkably during 2000s (Fig. S5). Consequently, it seems LHF does not always linearly respond to precipitation, but exhibit a threshold feature (Fig. 13a), which resembles the soil moisture-evapotranspiration coupling ${ }^{7}$.

The first SVD mode between annual precipitation and SHF accounts for $24.0 \%$ of total covariance, much higher than the second $(10.6 \%)$ and third $(7.6 \%)$ modes. Contrary to LHF, the spatial pattern of the first mode 

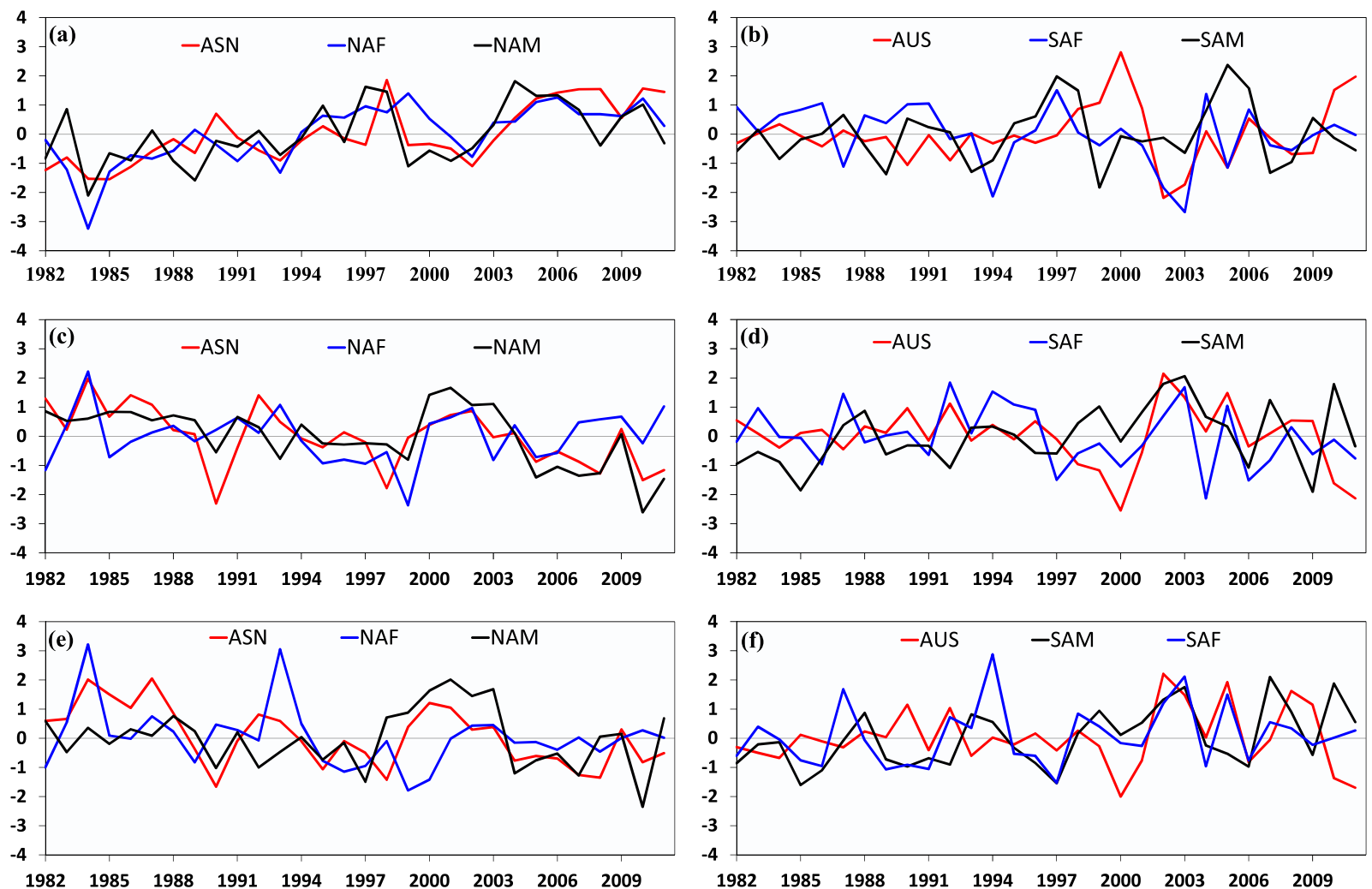

Figure 10. Variations in $\operatorname{LHF}(\mathbf{a}, \mathbf{b}), \operatorname{SHF}(\mathbf{c}, \mathbf{d})$, and Bowen ratio (e,f) for six monsoon sectors in Northern and Southern Hemisphere. For comparison, here the LHF, SHF and Bowen ratio are normalized by their maximums (that is, the maximums of time series) in each monsoon sector.

of SHF is oppositely matched by that of precipitation (Fig. 11c). The increase (decrease) in SHF is closely related to the decrease (increase) in precipitation in all monsoon sectors. Similar to LHF, the spatial pattern of the first mode of SHF is also consistent with the trend patterns shown in Fig. 6b, which further confirms the role of precipitation played in the trends of SHF. Moreover, SHF is more sensitive than LHF to the variation in precipitation (Fig. 12). The correlation coefficients between SHF and precipitation are 0.858, 0.432, 0.754, 0.716, 0.664, 0.476 , and 0.830 for AUS, NAF, SAF, ASN, NAM, SAM, and EASN respectively, which are statistically significant $(p<0.01)$ and are higher than the correlation coefficients between LHF and precipitation except NAF (Fig. 13c). However, the SHF-precipitation correlation is not sensitive to the precipitation amount itself (Fig. 13a). SHF shows strong linear response to precipitation even in wet climate regimes such as SAM, NAM and EASN, which is different from LHF.

Similar to SHF, the spatial pattern of the first mode of Bowen ratio is also oppositely matched by that of precipitation (Fig. 11f), which accounts for $26.4 \%$ of total covariance. The increase (decrease) in Bowen ratio is closely related to the decrease (increase) in precipitation. Moreover, Bowen ratio shows strong negative correlation with precipitation in all monsoon domains (Fig. 12), with the correlation is significant at $99 \%$ level except SAM (Fig. 13c). In addition, the Bowen ratio-precipitation correlation is sensitive to the precipitation amount itself. But there seems no threshold feature is observed that appears in the LHF-precipitation correlation (Fig. 13a).

Therefore, the trend pattern (LHF+, SHF-) dominant in ASN, NAF and AUS and the trend (LHF-, SHF-) dominant in SAF are sensitive to the variation in precipitation. However, the trend patterns $(\mathrm{LHF}+, \mathrm{SHF}+)$ that dominates in the SAM and ( $\mathrm{LHF}+, \mathrm{SHF}-$ ) that dominates in NAM only partially responds to precipitation. The SAM and NAM have excessive precipitation and are covered by a wide stretch tropical rainforest (that is, the Amazon rainforest), which makes their LHF energy-limited and not sensitive to the variability in precipitation. In addition, the excessive precipitation may be largely turn into run-off and thus will not participate in evaporation over land. Moreover, as shown in Fig. 8b, the (LHF, SHF) pattern based on the heterogeneous correlation coefficient patterns of SVD first modes highly matches the (LHF, SHF) trend pattern showed in Fig. 8a. The spatial consistency indicates precipitation indeed exerts significant impacts on the land surface energy partitioning in monsoon domains.

The first principal components of the first modes of SVD analysis between precipitation and LHF, SHF and Bowen ratio are also presented (Fig. 11b,d,f). Dramatic phase shifts of the first principal components are observed in the late-1990s. Notably, it concurs with the strong ENSO event during 1998-1999 and the shift in ENSO EN. $^{39}$ Both LHF and precipitation shift from negative to positive phases in monsoon domains. In contrast, SHF was in positive phase before late-1990s and in negative phase afterwards. Notably, phase shifts in LHF and SHF are also observed in non-monsoon domains. But the shifts for the drylands are in opposite directions to those in monsoon domains (Figs. 11a,c). Consequently, the phase shifts of land surface energy partitioning occur globally in 
(a) Heterogeneous correlation coefficient of SVD1 (27.8\%)

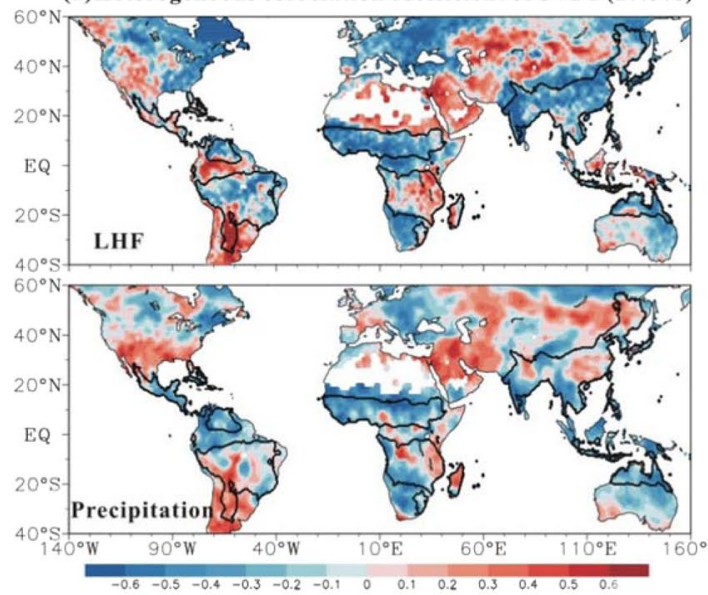

(c)Heterogeneous correlation coefficient of SVD1 (24.0\%)
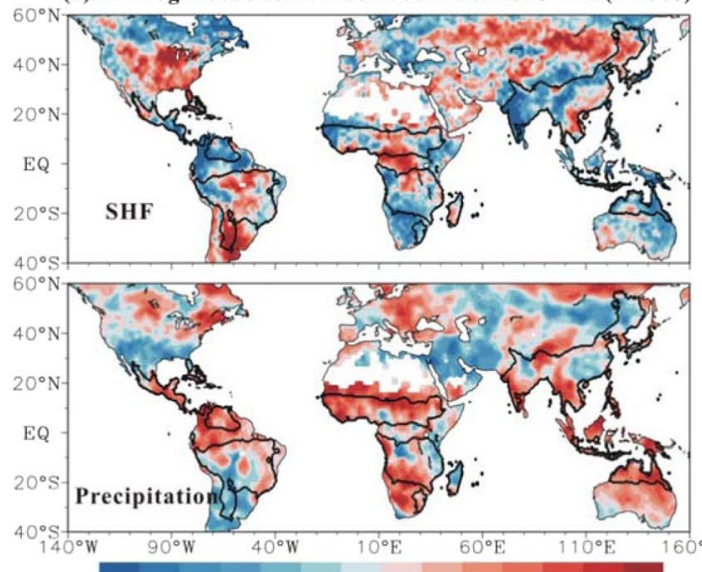

(e)Heterogeneous correlation coefficient of SVD1 (26.4\%)
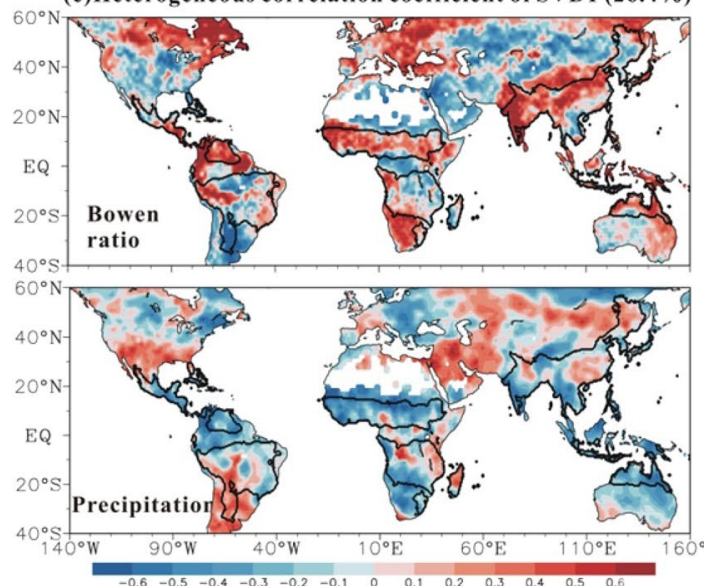

(b) PC1 of LHF and precipitation

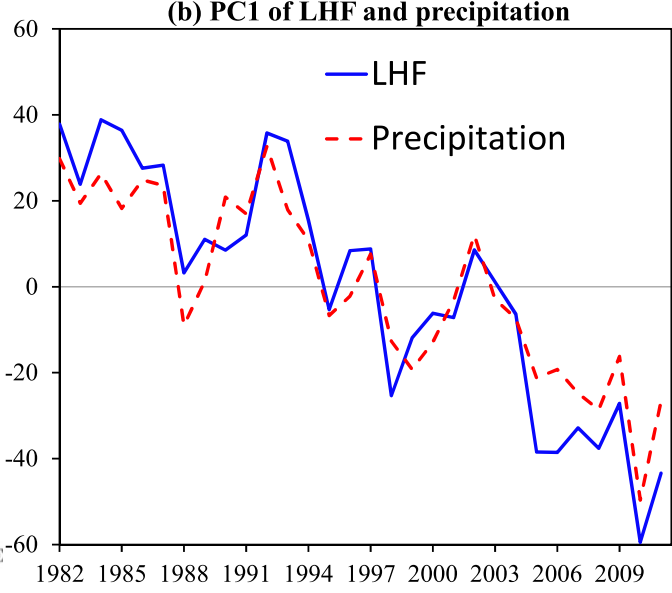

(d) PC1 of SHF and precipitation

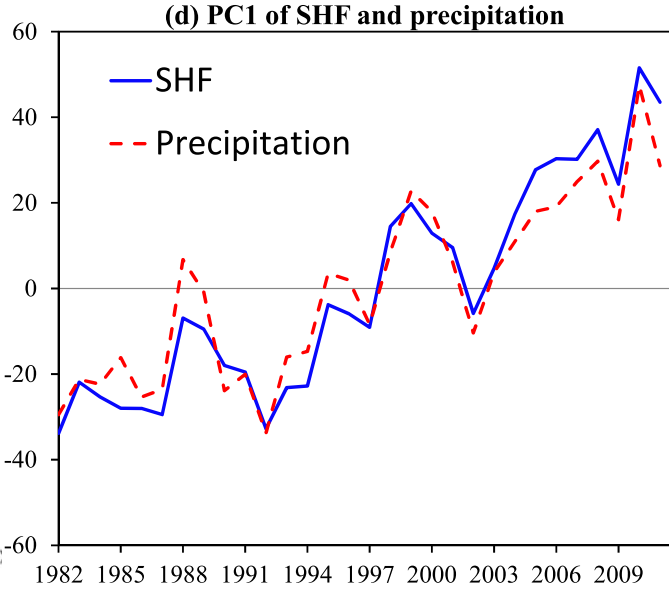

(f) PC1 of SHF and precipitation

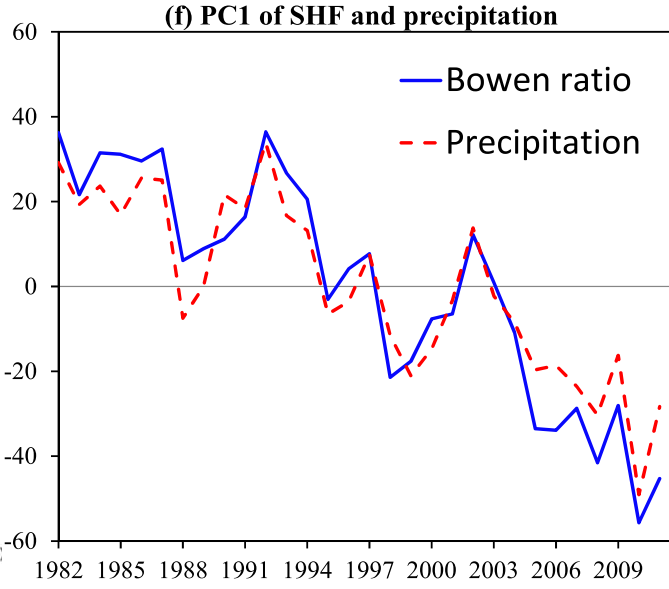

Figure 11. The primary modes of SVD analysis between mean annual LHF, SHF, and Bowen ratio and precipitation for the period of 1982-2011. (a,c,e) the heterogeneous correlation coefficient patterns; (b,d,f) the corresponding time series. The explained covariance is given in the parentheses above $(\mathbf{a}, \mathbf{c}, \mathbf{e})$.

response to variation of precipitation under the global warming, but they seem contrary in monsoon domains and drylands. These shifts might be controlled by natural variability. The Atlantic multidecadal oscillation has also experienced a remarkable phase shift from previous negative phases to post positive phases around the mid-1990s ${ }^{40,41}$.

The relations between monsoon and LHF, SHF and Bowen ratio. In the monsoon domains, monsoon strength has significant control on precipitation and thus influences on the land surface fluxes (Fig. 3). SVD analysis is also performed on monsoon strength and LHF, SHF and Bowen ratio. The results resemble those of precipitation and thus no figures are presents. The first SVD modes (figures not shown) between monsoon 

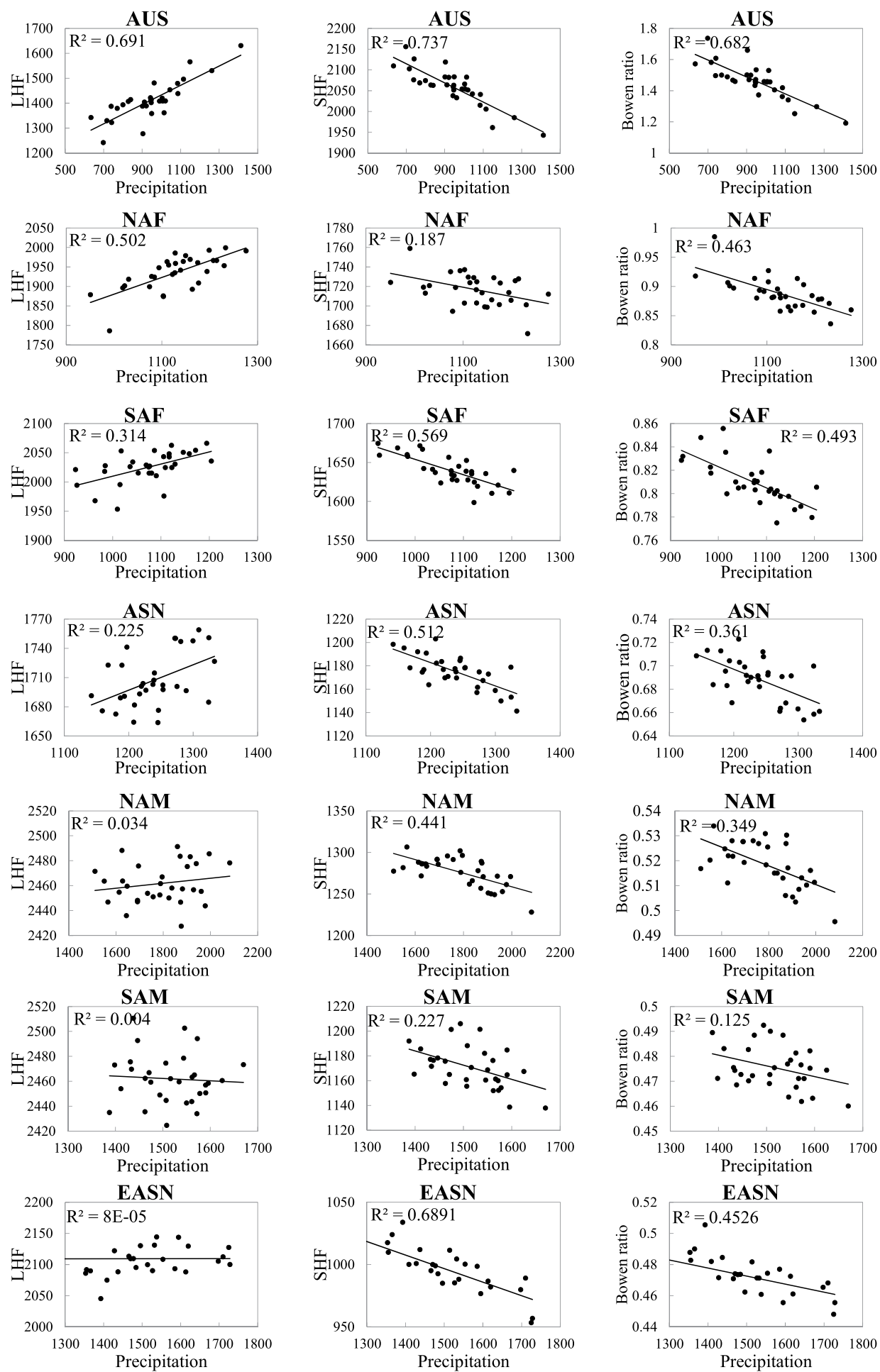

Figure 12. Relations between annual precipitation (in $\mathrm{mm} \mathrm{yr}^{-1}$ ) and LHF (left panel, in $\mathrm{MJ} \mathrm{m}^{-2} \mathrm{yr}^{-1}$ ), SHF (middle panel, in $\mathrm{MJ} \mathrm{m}^{-2} \mathrm{yr}^{-1}$ ), and Bowen ratio (right panel) among monsoon domains for the period of 1982-2011.

strength and LHF, SHF and Bowen ratio explain 25.2\%, 22.2\% and $24.0 \%$ of total covariance, respectively. The spatial patterns of the first modes of LHF, SHF and Bowen ratio closely match that of monsoon strength. On regional scale, similar to precipitation, monsoon strength also significantly $(p<0.01)$ correlates with LHF and SHF (Figs. 13c and 14). The stronger monsoon often results in larger LHF and smaller SHF. However, the LHF-monsoon strength correlation shows high sensitivity to monsoon strength itself (Fig. 13b). No obvious relation between LHF and monsoon is observed in weak monsoon domains NAM and SAM where weak response of LHF to precipitation is also observed. But there exist some differences in the responses of land surface fluxes 

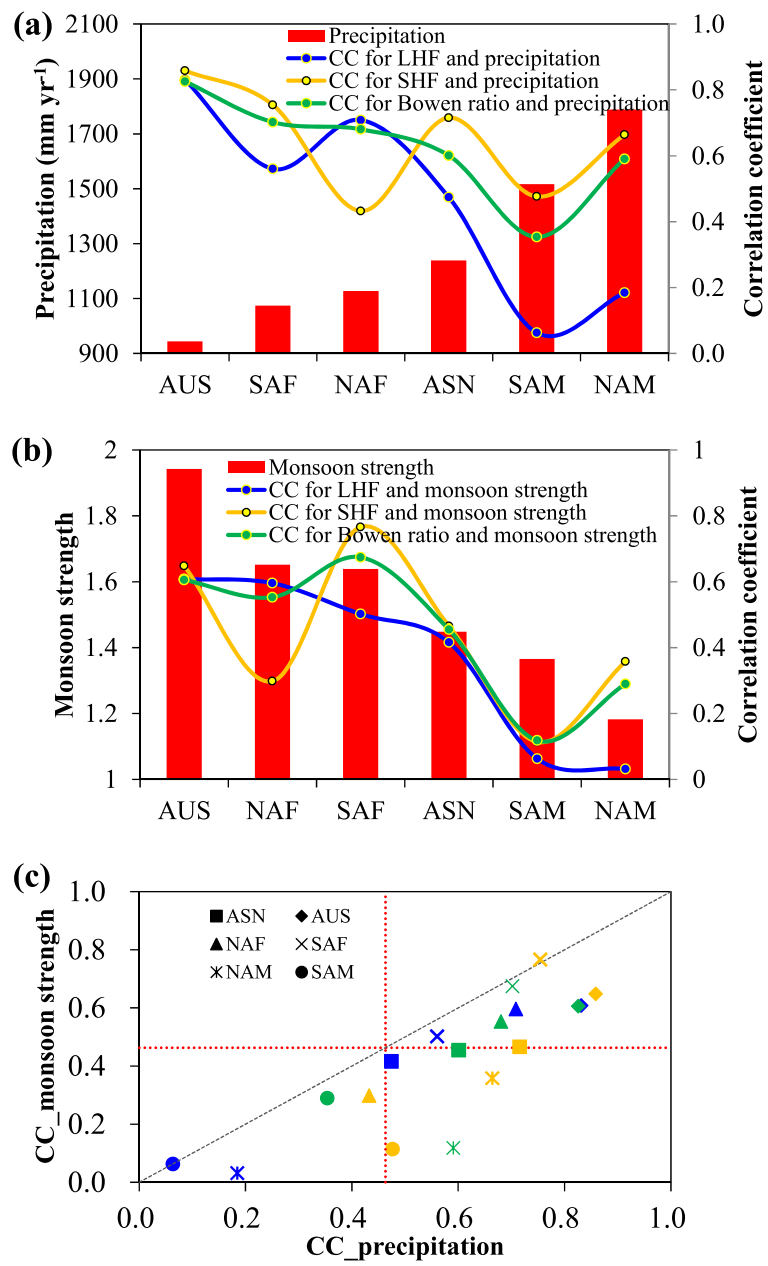

Figure 13. The Correlation coefficients (CCs) of LHF (blue), SHF (yellow) and Bowen ratio (green) with precipitation and monsoon strength for six monsoon sectors. $(\mathbf{a}, \mathbf{b})$ The precipitation and monsoon strength are shown by red column. (c) The $\mathrm{x}$-axis and y-axis are the CCs related to precipitation and monsoon strength, respectively. The CCs for each sector are marked with different symbols. The grey dashed line is the 1:1 line. The red dashed lines denote the CC threshold that is statistically significant $(p<0.01)$ based on student's t-test.

to monsoon strength and precipitation. For example, monsoon seems to have weak constraints on SHF in SAM and NAM where SHF significantly correlates with precipitation. Moreover, the responses of LHF, SHF and Bowen ratio to monsoon strength are less robust than to precipitation (Fig. 13c), which is primarily attributed to the fact that precipitation exerts more direct influences on land surface energy partitioning.

\section{Summary}

The land surface LHF and SHF are key energy sources that drive atmosphere circulation, and thus are closely linked with weather and climate changes. In this paper, we investigate the long-term mean, trends and leading modes of land surface LHF, SHF and Bowen ratio in global land monsoon domains. The responses of LHF, SHF and Bowen ratio to monsoon and precipitation are also discussed.

As expected, LHF dominated in monsoon domains and the mean LHF is about one quarter larger than SHF. During the past three decades, LHF and SHF show three dominant trend patterns in global terrestrial monsoon domains. The first is (LHF+, SHF-) dominated in ASN, AUS, NAF, NAM monsoon sectors. Moreover, the increasing rate of LHF was higher than the decreasing rate of SHF, which resulted in a decreased trend in Bowen ratio. This implies the energy needed by increased LHF is only partially due to the decreased SHF and the remaining is associated with an increase in land surface net radiation. Similar relations among LHF, SHF and net radiation are discussed over urban land surfaces ${ }^{42}$. The trend patterns (LHF+, SHF+) and (LHF-, SHF-) are dominated in SAM and SAF, respectively. In contrast, (LHF-, SHF+) is dominated only in drylands. These trends result in remarkable phase shifts in LHF and SHF in both monsoon domains and drylands during late1990s. LHF shifts from negative to positive phase and SHF from the positive to negative in the monsoon domains. But the shifts are in reversed direction in drylands. The distinctions between monsoon domains and drylands suggest that climate is generally becoming wetter in monsoon regions but drier in drylands with global warming during the past three decades.

The variability and regional difference in LHF, SHF and Bowen ratio are found to be closely linked to precipitation and monsoon strength. On regional scale, precipitation significantly positively correlates with LHF in AUS, 

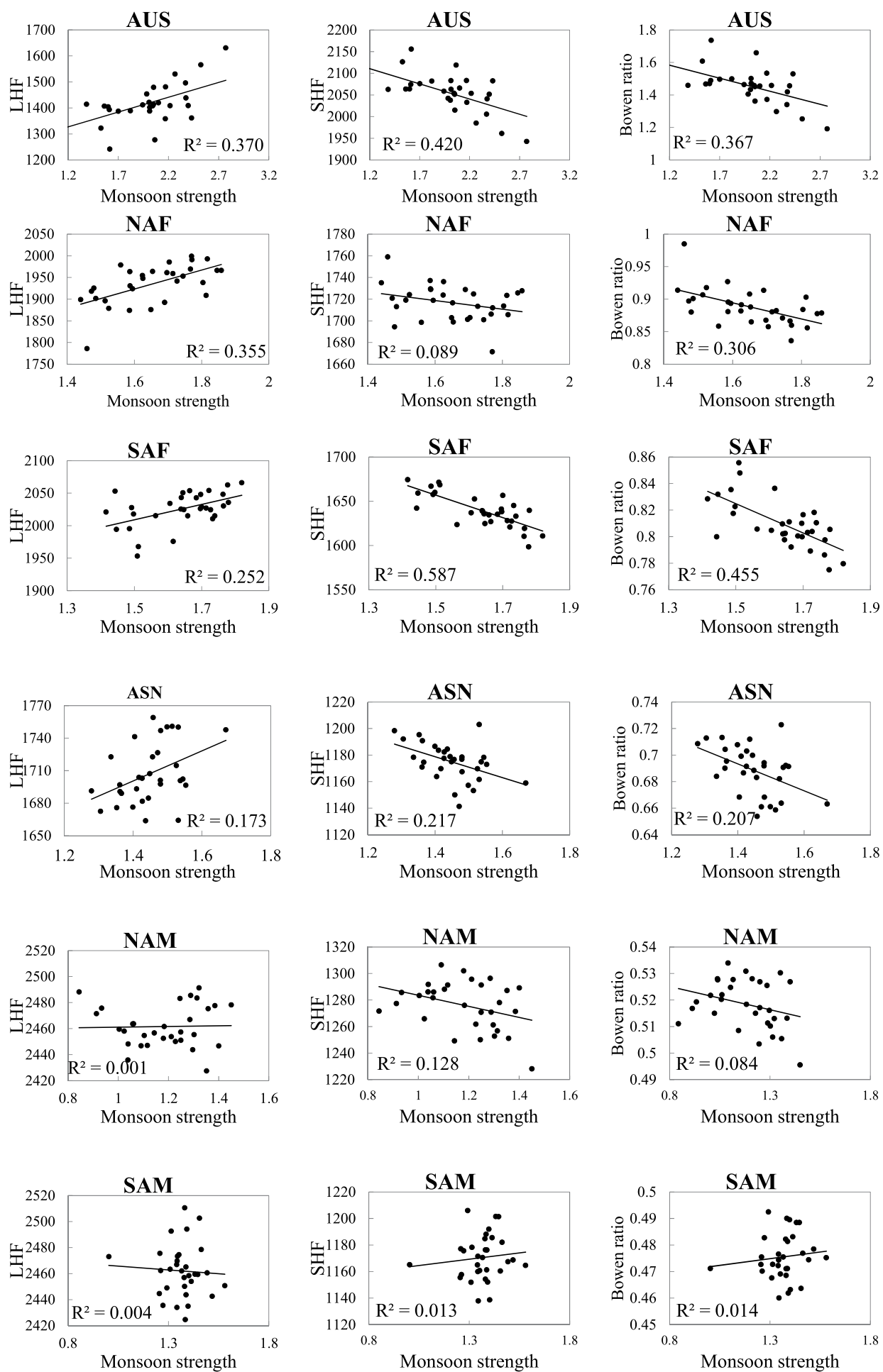

Figure 14. Relations between monsoon strength and LHF (left panel, in $\mathrm{MJ} \mathrm{m}^{-2} \mathrm{yr}^{-1}$ ), SHF (middle panel, in $\mathrm{MJ} \mathrm{m}^{-2} \mathrm{yr}^{-1}$ ), and Bowen ratio (right panel) among monsoon domains for the period of 1982-2011.

NAF, SAF and ASN where the mean annual precipitation is below $1300 \mathrm{~mm} \mathrm{yr}^{-1}$, but weakly correlates with LHF in NAM, SAM and EASN where the mean annual precipitation is over $1400 \mathrm{~mm} \mathrm{yr}^{-1}$. It seems the response of LHF to precipitation is weak in more humid monsoon climates but shows strong linearity in less humid monsoon climates. Significant negative correlations between precipitation and SHF and Bowen ratio are observed in all monsoon sectors. Moreover, SVD analyses show that precipitation explains $27.8 \%, 24 \%$ and $26.4 \%$ total covariance of LHF, SHF and Bowen ratio, respectively, in the primary modes. The spatial patterns of the first modes of LHF, SHF and Bowen ratio are closely matched by that of precipitation, which indicates the strong regulation of precipitation on land surface energy partitioning on pixel scale. Precipitation on one hand favors more land 
surface available energy being converted into LHF, on the other it enhances the LHF by increasing the land surface net radiation. The intensifying LHF and precipitation means acceleration of hydrological cycle in global land monsoon domains, which is consistent with previous studies and may have substantial impact on the availability and distribution of water as well as the ecosystems upon which we depend ${ }^{43,44}$. Additionally, since precipitation and monsoon strength are closely related, the responses of LHF, SHF and Bowen ratio to monsoon strength resemble that to precipitation but less robust.

Finally, the work is based on the upscaled product of FLUXNET observations, which might introduce some uncertainties in regions where observations are rare or even unavailable. For instance, FLUXNET has very few observations from India, and the observation sites are sparse in Africa. The conclusions on trends of land surface heat fluxes in these regions should be taken with caution.

Received: 19 May 2019; Accepted: 12 March 2020;

Published online: 01 April 2020

\section{References}

1. Acharya, R. H., Sigdel, M., Ma, Y. \& Wang, B. Diurnal and seasonal variation of heat fluxes over an agricultural field in southeastern Nepal. Theor Appl Climatol, https://doi.org/10.1007/s00704-019-02790-3 (2019).

2. Vote, C., Hall, A. \& Charlton, P. Carbon dioxide, water and energy fluxes of irrigated broad-acre crops in an Australian semi-arid climate zone. Env. Earth Sci. 73, 449-465, https://doi.org/10.1007/s12665-014-3547-4 (2015).

3. Shukla, J. \& Mintz, Y. Influence of Land-Surface Evapotranspiration on the Earth's Climate. Science 4539, 1498-1501, https://doi. org/10.1126/science.215.4539.1498 (1982).

4. DeFries, R. S., Bounoua, L. \& Collatz, G. J. Human modification of the landscape and surface climate in the next fifty years. Glob. Change Biol. 8, 438-458, https://doi.org/10.1046/j.1365-2486.2002.00483.x (2002).

5. Sterling, S., Ducharne, A. \& Polcher, J. The impact of global land-cover change on the terrestrial water cycle. Nat. Clim. Change 3 , 13688, https://doi.org/10.1038/nclimate1690 (2013).

6. Zeng, Z. et al. Impact of Earth Greening on the Terrestrial Water Cycle. J Climate 31, https://doi.org/10.1175/JCLI-D-17-0236.1 (2018).

7. Seneviratne, S. I. et al. Investigating soil moisture-climate interactions in a changing climate: A review. Earth-Sci Rev. 99, 125-161, https://doi.org/10.1016/j.earscirev.2010.02.004 (2010).

8. Mohtadi, M., Prange, M. \& Steinke, S. Palaeoclimatic insights into forcing and response of monsoon rainfall. Nature 533, 191-199, https://doi.org/10.1038/nature17450 (2016).

9. Hsu, P. C., Li, T. \& Wang, B. Trends in global monsoon area and precipitation over the past 30 years. Geophys Res Lett 38, https://doi. org/10.1029/2011gl046893 (2011)

10. Wang, B., Liu, J., Kim, H. J., Webster, P. J. \& Yim, S. Y. Recent change of the global monsoon precipitation (1979-2008). Clim. Dyn. 39, 1123-1135, https://doi.org/10.1007/s00382-011-1266-z (2012).

11. Zhou, T. J., Yu, R. C., Li, H. M. \& Wang, B. Ocean forcing to changes in global monsoon precipitation over the recent half-century. J. Clim. 21, 3833-3852, https://doi.org/10.1175/2008JCLI2067.1 (2008).

12. Lee, J. Y. \& Wang, B. Future change of global monsoon in the CMIP5. Clim. Dyn. 42, 101-119, https://doi.org/10.1007/s00382-0121564-0 (2014).

13. Trenberth, K. E. et al. In Climate Change 2007: The Physical Science Basis (eds. Solomon, S. et al.) 235-336 (Cambridge University Press, 2007).

14. Council, N. R. Earth Science and Applications from Space: National Imperatives for the Next Decade and Beyond. 1-400 (Natl. Acad. Press, 2017).

15. Baldocchi, D. et al. FLUXNET: A new tool to study the temporal and spatial variability of ecosystem-scale carbon dioxide, water vapor, and energy flux densities. B Am Meteorol Soc 82, 2415-2434, doi:10.1175/1520-0477(2001)082<2415:Fantts $>2.3$.Co;2 (2001).

16. Novick, K. A. et al. The AmeriFlux network: A coalition of the willing. Agr. For. Meteorol. 249, 444-456, https://doi.org/10.1016/j. agrformet.2017.10.009 (2018)

17. Jung, M., Reichstein, M. \& Bondeau, A. Towards global empirical upscaling of FLUXNET eddy covariance observations: validation of a model tree ensemble approach using a biosphere model. Biogeosciences 6, 2001-2013, https://doi.org/10.5194/bg-6-2001-2009 (2009).

18. Jung, M. et al. Global patterns of land-atmosphere fluxes of carbon dioxide, latent heat, and sensible heat derived from eddy covariance, satellite, and meteorological observations. J Geophys Res-Biogeo 116, https://doi.org/10.1029/2010jg001566 (2011).

19. Ramage, C. S. Monsoon Meteorology. 1-296 (Academic Press, 1971).

20. Webster, P. J. et al. Monsoons: Processes, predictability, and the prospects for prediction. J. Geophys. Res-Oceans 103, 14451-14510, https://doi.org/10.1029/97jc02719 (1998).

21. Wang, B. \& Ding, Q. H. Global monsoon: Dominant mode of annual variation in the tropics. Dynam Atmos. Ocean. 44, 165-183, https://doi.org/10.1016/j.dynatmoce.2007.05.002 (2008).

22. Yang, L. B., Sun, G. Q., Zhi, L. \& Zhao, J. J. Negative soil moisture-precipitation feedback in dry and wet regions. Sci. Rep-Uk 8, 4026, https://doi.org/10.1038/S41598-018-22394-7 (2018).

23. Zhang, Q., Yang, Z., Hao, X. \& Yue, P. Conversion features of evapotranspiration responding to climate warming in transitional climate regions in northern China. Clim. Dyn. 52, 3891-3903, https://doi.org/10.1007/s00382-018-4364-3 (2019).

24. Harris, I., Jones, P. D., Osborn, T. J. \& Lister, D. H. Updated high-resolution grids of monthly climatic observations - the CRU TS3.10 Dataset. Int. J. Climatol. 34, 623-642, https://doi.org/10.1002/joc.3711 (2014).

25. Sheffield, J., Wood, E. F. \& Roderick, M. L. Little change in global drought over the past 60 years. Nature 491, 435-438, https://doi. org/10.1038/nature11575 (2012).

26. van der Schrier, G., Barichivich, J., Briffa, K. R. \& Jones, P. D. A scPDSI-based global data set of dry and wet spells for 1901-2009. J. Geophys. Research: Atmospheres 118, 4025-4048, https://doi.org/10.1002/jgrd.50355 (2013).

27. van der Schrier, G., Jones, P. D. \& Briffa, K. R. The sensitivity of the PDSI to the Thornthwaite and Penman-Monteith parameterizations for potential evapotranspiration. J Geophys Res-Atmos 116, https://doi.org/10.1029/2010jd015001 (2011).

28. Lawler, J. J. et al. Projected climate-induced faunal change in the Western Hemisphere. Ecology 90, 588-597, https://doi. org/10.1890/08-0823.1 (2009).

29. Rowhani, P., Lobell, D. B., Linderman, M. \& Ramankutty, N. Climate variability and crop production in Tanzania. Agr. For. Meteorol. 151, 449-460, https://doi.org/10.1016/j.agrformet.2010.12.002 (2011).

30. Jones, P. D. et al. Long-term trends in precipitation and temperature across the Caribbean. Int. J. Climatol. 36, 3314-3333, https:// doi.org/10.1002/joc.4557 (2016).

31. Hsu, P.-c., Li, T. \& Wang, B. Trends in global monsoon area and precipitation over the past 30 years. Geophysical Research Letters GEOPHYS RES LETT 38, https://doi.org/10.1029/2011GL046893 (2011). 
32. Lin, R., Zhou, T. \& Qian, Y. Evaluation of Global Monsoon Precipitation Changes based on Five Reanalysis Datasets. J. Clim. 27, 1271-1289, https://doi.org/10.1175/JCLI-D-13-00215.1 (2014).

33. Kanamitsu, M. et al. NCEP-DOE AMIP-II Reanalysis (R-2). B Am. Meteorol. Soc. 83, 1631-1644, https://doi.org/10.1175/bams-83$11-1631(2002)$

34. Wild, M., Grieser, J. \& Schaer, C. Combined surface solar brightening and increasing greenhouse effect support recent intensification of the global land-based hydrological cycle. Geophys. Res. Lett. 35, L17706, https://doi.org/10.1029/2008gl034842 (2008).

35. Wild, M. Global dimming and brightening: A review. J Geophys Res-Atmos 114, https://doi.org/10.1029/2008jd011470 (2009).

36. Dee, D. P. et al. The ERA-Interim reanalysis: configuration and performance of the data assimilation system. Q. J. Roy. Meteor. Soc. 137, 553-597, https://doi.org/10.1002/qj.828 (2011).

37. Zeng, Z. Z. et al. A worldwide analysis of spatiotemporal changes in water balance-based evapotranspiration from 1982 to 2009 . J. Geophys. Res-Atmos 119, 1186-1202, https://doi.org/10.1002/2013JD020941 (2014).

38. Qian, Y. T., Hsu, P. C. \& Cheng, C. H. Changes in Surface Energy Partitioning in China over the Past Three Decades. Adv. Atmos. Sci. 34, 635-649, https://doi.org/10.1007/s00376-016-6194-8 (2017).

39. Hu, Z. Z. et al. Weakened Interannual Variability in the Tropical Pacific Ocean since 2000. J. Clim. 26, 2601-2613, https://doi. org/10.1175/JCLI-D-12-00265.1 (2013).

40. Kamae, Y., Li, X., Xie, S.-P. \& Ueda, H. Atlantic effects on recent decadal trends in global monsoon. Climate Dynamics, 1-13, https:// doi.org/10.1007/s00382-017-3522-3 (2017).

41. Wang, B. et al. Northern Hemisphere summer monsoon intensified by mega-El Niño/Southern Oscillation and Atlantic Multidecadal Oscillation. Proceedings of the National Academy of Sciences of the United States of America 110, https://doi. org/10.1073/pnas.1219405110 (2013).

42. Brownlee, J., Ray, P., Tewari, M. \& Tan, H. Relative Role of Turbulent and Radiative Flux on the Near-Surface Temperature in a Single-Layer Urban Canopy Model over Houston. j. Appl Meteorol Clim 56, https://doi.org/10.1175/JAMC-D-17-0088.1 (2017).

43. Huntington, T. G. Evidence for intensification of the global water cycle: review and synthesis. J. Hydrol. 319, 0-95, https://doi. org/10.1016/j.jhydrol.2005.07.003 (2006).

44. McNeeley, S. et al. Catalyzing Frontiers in Water-Climate-Society Research A View from Early Career Scientists and Junior Faculty. B Am. Meteorol. Soc. 93, 477-484, https://doi.org/10.1175/BAMS-D-11-00221.1 (2012).

45. Huang, J. P., Yu, H. P., Dai, A. G., Wei, Y. \& Kang, L. T. Drylands face potential threat under 2 degrees C global warming target. Nat. Clim. Change 7, 417-422, https://doi.org/10.1038/Nclimate3275 (2017).

\section{Acknowledgements}

This work was supported by the Natural Science Foundation of China (41630426 and 41875022). We thank the following data providers: the upscaled FLUXNET dataset from the Max Planck Institute for Biogeochemistry, the precipitation and potential evapotranspiration data from Climatic Research Unit (CRU).

Author contributions

J.Z. and Q.Z. conceived the research. J.Z. performed the programming and data analysis and wrote the manuscript. All authors participated in discussions, contributed ideas, read and reviewed the manuscript.

\section{Competing interests}

The authors declare no competing interests.

\section{Additional information}

Supplementary information is available for this paper at https://doi.org/10.1038/s41598-020-62467-0.

Correspondence and requests for materials should be addressed to Q.Z.

Reprints and permissions information is available at www.nature.com/reprints.

Publisher's note Springer Nature remains neutral with regard to jurisdictional claims in published maps and institutional affiliations.

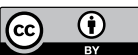

Open Access This article is licensed under a Creative Commons Attribution 4.0 International License, which permits use, sharing, adaptation, distribution and reproduction in any medium or format, as long as you give appropriate credit to the original author(s) and the source, provide a link to the Creative Commons license, and indicate if changes were made. The images or other third party material in this article are included in the article's Creative Commons license, unless indicated otherwise in a credit line to the material. If material is not included in the article's Creative Commons license and your intended use is not permitted by statutory regulation or exceeds the permitted use, you will need to obtain permission directly from the copyright holder. To view a copy of this license, visit http://creativecommons.org/licenses/by/4.0/.

(c) The Author(s) 2020 